\title{
Influence of Form and Orientation of Single Abrasive Grits on Their Strength Characteristics
}

\author{
Vladimir Lyukshin \\ Department of metal-cutting machines \\ and tools \\ T.F. Gorbachev Kuzbass State \\ Technical University \\ Kemerovo, Russia \\ lwsfoa@ rambler.ru \\ Larisa Shutko \\ Department of economy \\ T.F. Gorbachev Kuzbass State \\ Technical University \\ Kemerovo, Russia \\ shig.etf@kuzstu.ru
}

\author{
Dmitry Shatko \\ Department of metal-cutting machines \\ and tools \\ T.F. Gorbachev Kuzbass State \\ Technical University \\ Kemerovo, Russia \\ shdb.tm@kuzstu.ru
}

\author{
Pavel Strelnikov \\ Department of foreign languages \\ T.F. Gorbachev Kuzbass State \\ Technical University \\ Kemerovo, Russia \\ strelnikovpa@kuzstu.ru
}

\begin{abstract}
The article is devoted to the research of strength properties of single abrasive grits of various shapes. The existing methods for determining the strength of abrasive materials are analyzed. Data are presented on the pattern of stresses arising in abrasive grits under various schemes of applying loads to them, obtained by computer simulation. The results of static strength tests of regular alumina grains by the method of uniaxial compression, as well as observations of the influence of the orientation and shape of abrasive grits on its impact strength, are presented.
\end{abstract}

Keywords-rupture of brittle materials, strength, impact strength, grain shape, grain orientation, stress distribution, loading conditions, internal stress, cutting force

\section{INTRODUCTION}

One of the priority ways of development of domestic engineering is the development of advanced science intensive methods of processing parts, leading to improved quality and processing productivity. Such methods include the development of fundamentally new designs of grinding tools containing in their structure abrasive grits of a certain shape and orientation. A lot of works devoted to the study of the influence of the shape and orientation of abrasive grains on the performance characteristics of various grinding tools convincingly prove the importance of this area of activity [1, 2, 4-16].

As is known, the process of grinding is characterized by the removal of a huge number of fine chips. A large number of abrasive grits participate in the work. In addition to these circumstances, the complexity of studying the characteristics of the grinding process is that the chip removal takes place in an exceptionally short period of time. As a result, the characteristics of the cutting process during grinding, as a rule, are evaluated by indirect methods, among which there is the study of the properties of single abrasive grits.

The process of brittle rapture of abrasive materials is characterized by instability, so its theoretical description raises certain difficulties. The existing rapture theories are based on empirical data and allow estimating the strength of brittle materials with a certain accuracy, without taking into account the dimensions, shape, internal and external defects. These properties are fully inherent in abrasive grains, so when studying their strength characteristics, it is not the theoretical approach that is appropriate, but the experimental one.

At present, the following approaches are used to study the strength of abrasive grits $[3,4]$ :

- grain grinding in a ball mill.

- grain rapture by uniaxial compression.

- micro-cutting with a single abrasive grit.

- grain rapture by a special striker, an oscillating weight and a weight falling from a certain height.

The above methods have inherent drawbacks due to the fact that these schemes do not fully reflect the loading schemes that are characteristic of actual grinding conditions.

The diagram of the forces acting on abrasive grit during cutting can be visualized in Figure 1. From the above diagram it can be seen that the following group of forces acts on abrasive grit:

- Fc (centrifugal), Py.n (normal) и Pz.n (tangential) on the front surface.

- Py.m (normal) и Pz.m (tangential) - on the main rear surface.

- Py.l (normal) и Pz.l (tangential) - on the lateral rear surfaces.

The listed forces are Ру. - normal и $\mathrm{Pz}$ - tangential components of the cutting force.

In order to ensure the maximum reliability in determining the strength of abrasive grits, one must strive to reproduce the real conditions for their loading.

Analyzing the relative approaches to the evaluation of strength, we can conclude that they do not give a full picture of the behavior of grain in the process of cutting. In this connection, it is advisable to use those methods that are as 
close as possible to the real conditions of the grain operation - uniaxial compression, recording the thickness of the cut chips, impact with an oscillating or falling weight. Studying the advantages and disadvantages of the indicated methods, it should be noted that the method of uniaxial compression due to the set of features looks most preferable for studying the strength characteristics of abrasive grits in the static state. As for the dynamic tests, the method for assessing the strength by an oscillating weight is the most suitable.

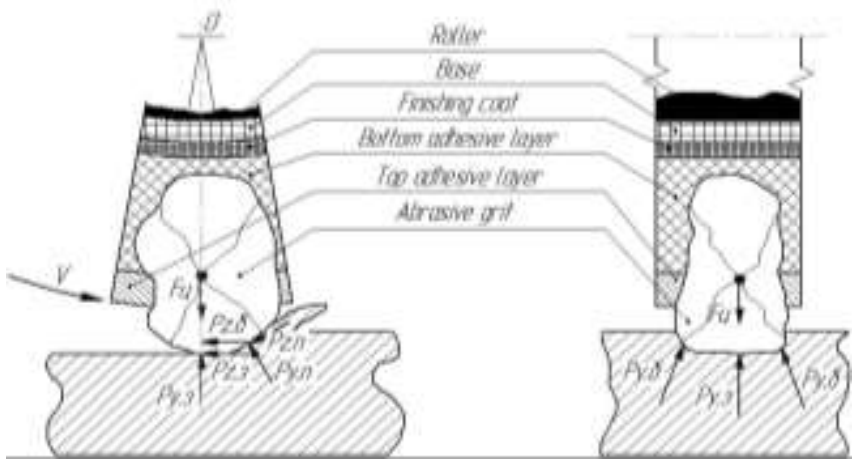

Fig. 1. Forces acting on single abrasive grit

\section{RESEARCH METHODS}

The theoretical method of studying stresses in grain models by the finite element method.

When studying the influence of the shape of the grain and the nature of the application of stress on the distribution of stresses in the abrasive grit body, the software "MSC / NASTRAN" was used. The abrasive grit models in the form of a cube, a lamel and a sphere corresponding to the real abrasive grits were used for the research. In the approximation adopted, the model in the form of a cube displays the grain of the intermediate form, in the form of a lamel - acicular (lamellar), and in the form of a sphere isometric form.

Since the location of abrasive grits in the tool affects the nature of the application of the load, 11 schemes of loading the models were studied.

Some of the most characteristic schemes of loading the models, as well as the resulting patterns of normal stresses generated by software, appear in table 1 .

TABLE I. PATTERNS OF NORMAL STRESSES IN MODELS OF ABRASIVE

\begin{tabular}{|l|c|c|}
\hline № & Stress distribution & $\begin{array}{c}\text { Patterns of normal } \\
\text { stresses }\end{array}$ \\
\hline 1 & & \\
\hline & & \\
\hline
\end{tabular}

\begin{tabular}{|c|c|c|}
\hline № & Stress distribution & $\begin{array}{c}\text { Patterns of normal } \\
\text { stresses }\end{array}$ \\
\hline 3 & & 0 \\
\hline
\end{tabular}

Evaluation of the strength of grains by the experimental method of uniaxial compression.

This method was implemented in practice using the laboratory setup shown in Figure 2.

The operation of the setup is based on the movement of the rod 3 by means of a hydraulic drive. The lower part 1 of the setup contains hydraulic pump, electric motor, distribution, control and monitoring equipment, control arms 2. A carbide tip is mounted on the rod of the hydraulic cylinder. The investigated grain is pressed against the carbide plate 4 of the load measuring unit 5 . The rapture force of the grain is fixed by a mechanical pointer force-measuring device 6 .

In the setup described above, the experiments were carried out to investigate the strength of grains of regular alumina 13A40. Abrasive grits of various shapes were used:

- $\quad$ isometric (shape coefficient $K_{\phi}=1.102$ ).

- intermediate $\left(\mathrm{K}_{\phi}=1.558\right)$.

- $\operatorname{acicular}\left(\mathrm{K}_{\phi}=2.241\right)$.

Since the rapture of abrasive grains is characterized by a large scatter in the experimental data, the multiple repetitions of the tests were used to increase the reliability, over a hundred times in the study of each of grain shape.

To carry out the tests, lamels with abrasive grains fixed on it perpendicular to it were used as samples. With this fixation, the axial force acts under the loading in the direction of the larger axis of the grain (Figure 3 ).
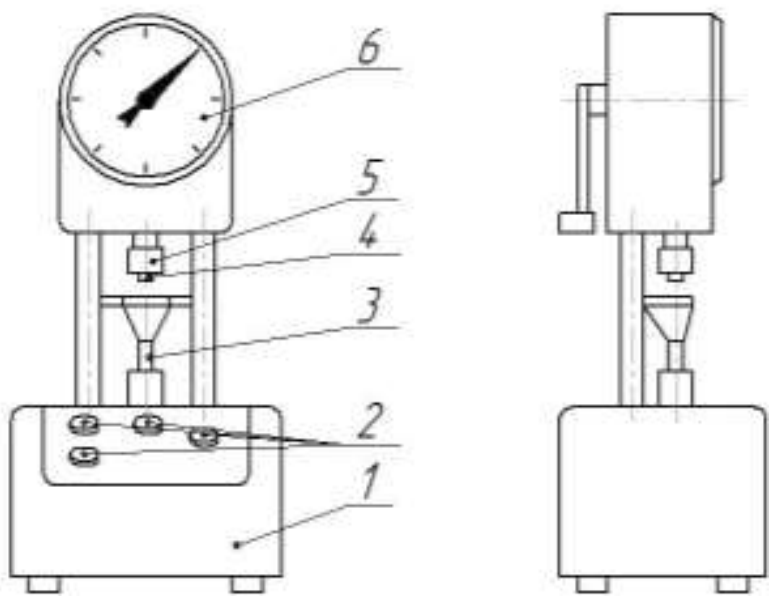

Fig. 2. Scheme of the setup for determining the strength of abrasive grits 


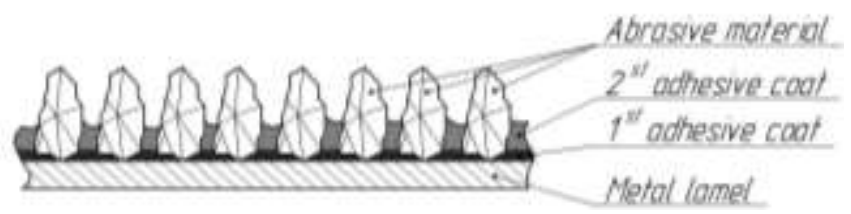

Fig. 3. Sample for strength tests

When processing the experimental data, the software package "STATISTICA 6.0"was used. In Figure 4 some data on the rapture forces $\mathrm{P}\left(\mathrm{kN} \cdot 10^{-2}\right)$ based on the results of 100 measurements of abrasive grits 13A40 (regular alumina) of various shapes are presented.

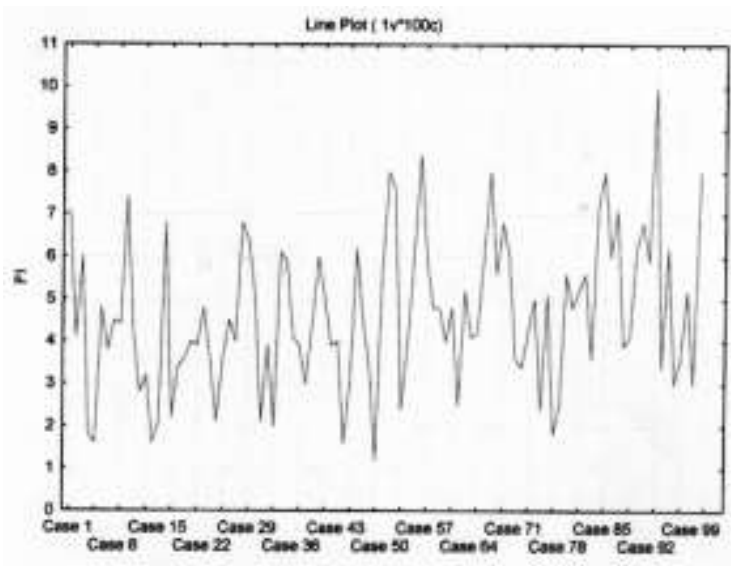

a)

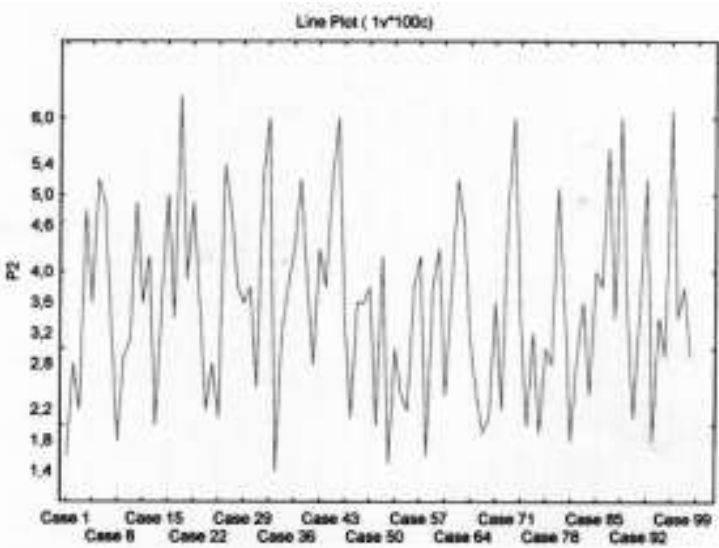

b)

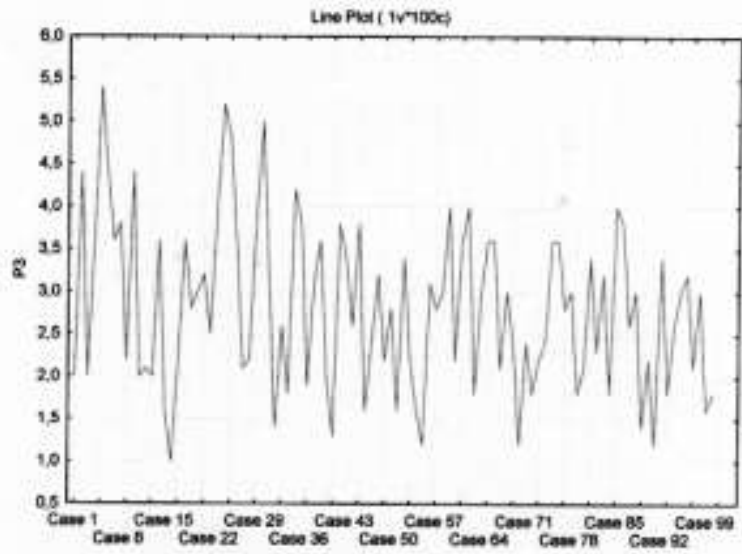

c)

Fig. 4. Rapture forces of grains of various shapes: a) isometric; b) intermediate; c) acicular
Evaluation of the strength of abrasive grits by the experimental method using an oscillating weight.

Since the abrasive grit operates with cyclically repeated short-time loads, approaches based on dynamic loading conditions will best reproduce the real picture of the loading. Such an approach involves evaluating the strength by means of an oscillating weight. In Figure 5 a schematic diagram of the specially designed device for determining the impact strength of single abrasive grit. The device contains the following parts: the pendulum 1 , the striker 2 , the adjustment mechanism 3 , the cage 4 , the trigger device 5, the scale 6 and the arrow 7.

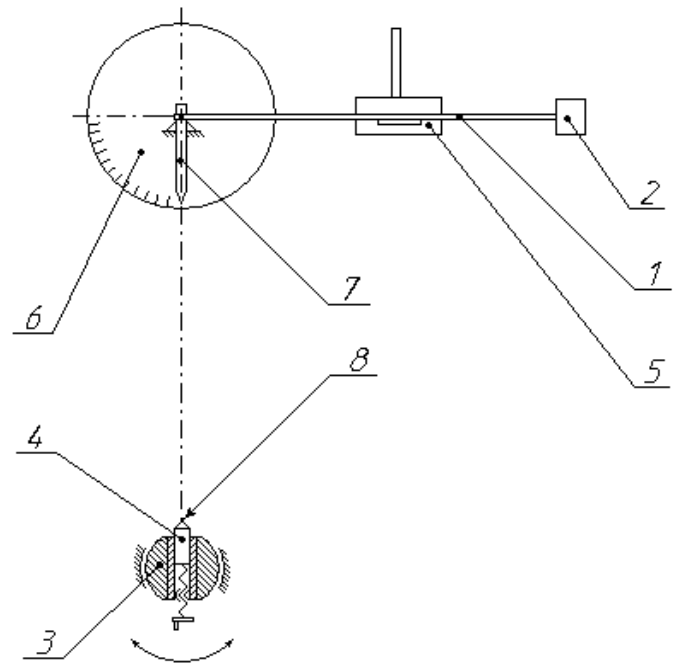

Fig. 5. Device for assessing the impact strength of a single abrasive grain

Operation of the device is as follows. The test grit 8 is fixed in the cage 4, which in turn is installed in the adjustment mechanism 3 , by means of which the cage 4 with the fixed abrasive grit is set to the required height, then rotated by the required angle. Further, the pendulum 1 with the striker 2 rises and is fixed in the device 5, when it operates, the pendulum with a striker under the action of gravity begins to move downward. When the bottom point is reached, the striker raptures the abrasive grit, after which the pendulum continues to move, deviating with respect to the vertical axis by a certain angle, which is measured along the scale 6 by the arrow 7 . The obtained value of the deflection angle allows judging the impact strength of the tested abrasive grit.

When testing for strength, $13 \mathrm{~A}$ grade abrasive grits (regular alumina) No.125, No.100, No.80 were used. In addition to domestic abrasives, the German regular alumina NK F24 No.80 was used. The grains were previously classified according to the shape into 3 varieties: isometric, intermediate and lamellar.

With respect to the horizontal, the angle of inclination of the grain $(\gamma)$ was taken in the following limits: $90^{\circ}, 75^{\circ}$ and $60^{\circ}$ (in the direction of impact). This made it possible to study the strength characteristics of grain, depending on its orientation.

To determine the impact strength of grinding grain ( $a$ ), the following formula was used: 


$$
a=\frac{U}{S},
$$

where $U$ - force impulse;

$S$ - surface area of the abrasive grit in the rapture zone.

Force impulse was determined from the following relationship:

$$
U=m \cdot\left(V_{x x}-V_{p x}\right),
$$

where $V_{x x}$ и $V_{p x}$ - respectively, the speed of the idling and operating strokes;

\section{$m$ - striker mass.}

The speeds of the idling and working strokes were calculated by the following formulas:

$$
\begin{aligned}
& V_{x x}=2 \cdot \sqrt{g \cdot l} \cdot \frac{\sin \alpha_{x x}}{2} \\
& V_{p x}=2 \cdot \sqrt{g \cdot l} \cdot \frac{\sin \alpha_{p x}}{2}
\end{aligned}
$$

where $g$ - acceleration of gravity;

$\alpha_{x x}$ и $\alpha_{p x}-$ angle of deviation of the pendulum from the equilibrium position, respectively, at the idling and operating strokes.

A special computer program was used to estimate the surface area of the grain rapture. For what the grain rapture surface was preliminary scanned, and the received images were processed by the given program. To ensure the reliability of the experimental data, each experiment was repeated at least 25 times.

\section{RESULTS AND DISCUSSION}

Theoretical method of studying stresses in grain models by the finite element method.

From the data given in Table 1, it can be seen that the nature of the application of the load to the grinding grain, as well as its shape, affect the magnitude of the resulting normal stresses in the grain structure, as well as its strength. Obviously, the grains that perceive the load with pointed portions (Scheme No.1) receive the greatest stresses near the peaks, which will lead to the chipping of small particles and, as a result, to self-sharpening.

Grains that absorb the load by flat areas (Scheme No.2) receive the greatest stresses immediately next to the place where the grains are embedded in the adhesive, which leads to breaking them out of the adhesive.

The distinctive feature of the loading with respect to the spherical model is the point-like form of the application of the load (Scheme No.3), this can contribute equally to the removal of grain from the adhesive (under the condition of applying a sufficiently large force) and to the rapture of the grain itself.

The results of modeling quite convincingly show that the shape and orientation of abrasive grits significantly affect the level of stresses arising in them, and, consequently, their strength.

Evaluation of the strength of grains by the experimental method of uniaxial compression.

Analysis of the dependences obtained experimentally makes it possible to confirm the results of mathematical modeling in that the strength characteristics of abrasive grits depend on their shape. Thus, the experimental data obtained make it possible to state that, on average, the force of rapture of isometric grains is 1.3 times higher than that of intermediate grains and 1.64 times higher than for acicular grains (see Figure 6).

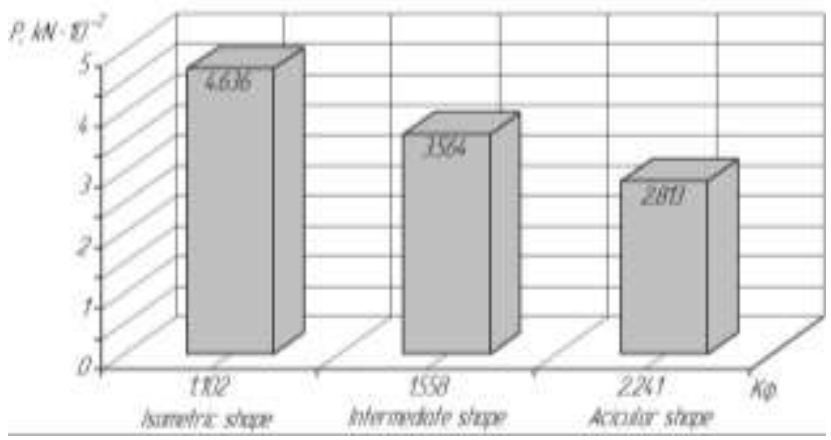

Fig. 6. The force of rapture of 13A40 (regular alumina) abrasive grits, depending on the shape factor

The data obtained suggest that the use of isometric grains in the structure of the grinding tool will help to increase the strength of micro-cutting elements. It is noted that the greater the coefficient of the shape of the grains of the acicular and intermediate shapes, so their strength is lower. This difference in strength, obviously, should also affect other performance indicators of grain and tools made from them.

Evaluation of the strength of abrasive grits by the experimental method using an oscillating weight.

The obtained experimental results (Figure 7) show that isometric grains are stronger than intermediate and acicular (lamellar) grains.

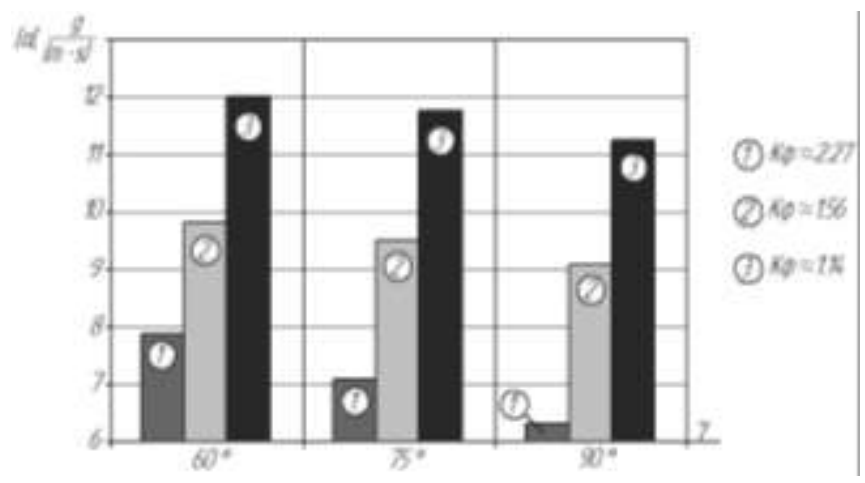

Fig. 7. Impact strength of $13 \mathrm{~A} 125$ abrasive grits, depending on their shape and orientation

It is noted that when the angle of inclination of the grain varies from $90^{\circ}$ to $60^{\circ}$ (in the direction of impact), the strength of the grains increases by:

- $7 \div 18 \%$ - when using $13 \mathrm{~A} 125$ abrasive.

- $10 \div 16 \%$ - when using 13 A100 abrasive. 
- $7 \div 18 \%$ - when using $13 \mathrm{~A} 80$ abrasive.

- $5 \div 17 \%$ - when using NK F24 abrasive.

In addition to the shape and orientation of abrasive GRITS, their strength is also significantly affected by their size and abrasive grade.

The processing of the experimental data was carried out using the software package "STATISTICA 6.0". With the help of this program, the relationship between the impact strength $(a)$ and the parameters of a single abrasive grit $\left(K_{\phi}\right.$, $\gamma$ ) was investigated in the form of:

$$
\ln a=a_{0}+a_{1} \cdot \ln K_{\phi}+a_{2} \cdot \ln \gamma
$$

The parameters of the statistical model describing the mechanism of the influence of the abrasive grade, the shape of abrasive grit, the orientation angle and the size of abrasive grit on its impact strength, are given in table 2 .

Table 2 presents:

$a_{0}$ - free term of the model;

$K_{\phi}$ - coefficient of abrasive grit form;

$\gamma$ - orientation angle of abrasive grit.

TABLE II. PARAMETERS OF STATISTICAL MODELS

\begin{tabular}{|c|c|c|}
\hline $\begin{array}{c}\text { Abrasive } \\
\text { material grade }\end{array}$ & Model terms & $\begin{array}{c}\text { Statistical model } \\
\text { coefficients }\end{array}$ \\
\hline \multirow{3}{*}{$13 \mathrm{~A} 125$} & $a_{0}$ & 3.802989 \\
\cline { 2 - 3 } & $\ln K_{\phi}$ & -0.752999 \\
\cline { 2 - 3 } & $\ln \gamma$ & -0.290076 \\
\hline
\end{tabular}

The analysis of these models shows that when the grain size decreases, the degree of influence of the shape on its impact strength decreases. The influence of the orientation of abrasive grit on the strength is practically independent of the grain size.

\section{CONCLUSIONS}

(1) The shape and orientation angle has a significant effect on the strength of abrasive grits in both static (the uniaxial compression method) and dynamic tests (impact strength testing).

(2) Analysis of grain models showed that the shape of abrasive grits and the nature of the application of the load significantly affect the level and nature of the distribution of stresses arising in them and, consequently, strength.

(3) Isometric grains are stronger than intermediate and acicular (lamellar) grains.
(4) The results of statistical processing confirm the previous model experiment. In particular, they show that when $K \phi$ and $\gamma$ increase (from $0^{\circ}$ to $90^{\circ}$ ) the impact strength of single abrasive grits decreases.

\section{REFERENCES}

[1] D. Dubinkin. Increasing the operational capabilities of snagging wheel by using controlled shape grinding grains: author's abstract of Cand. Sci. (Eng.) Dissertation: (05.03.01); Tomsk, Tomsk Polytechnic University, 2009.

[2] G. Dubov. Increase of serviceability of cutting-off grinding wheels on the basis of using controlled shape grinding grains: Cand. Sci. (Eng.) Dissertation: (05.03.01). - Kemerovo: KuzSTU, 2004.

[3] A. Korotkov, V. Bashtanov. The device for measuring the strength of abrasive grains: Materials of interregional research to practice conference, 27-28 April 2001. - Bijsk: AltSTU, 2001 - pp. 25-9.

[4] A. Korotkov. Performance properties of abrasive materials: monograph. - Krasnoyarsk: University press, 1992. - 122 p.

[5] V. Korotkov. Evaluation of tensile strength of grinding wheels // Progressive technologies and economics in engineering: Proceedings of the II All-Russian research to practice conference, 29-30 April 2004. - Yurga: Tomsk Polytechnic University, 2004. - Volume 1, pp. $122-123$.

[6] V. Korotkov. Thermal phenomena during grinding by cutting wheels with a controlled shape abrasive grains // Processing of metals, 2007, №4, pp. 28-29.

[7] Murdasov A.V., Khshivo L.N. Properties of abrasive grains depending on their shape // Proceedings of the Ural Branch of the All-Union Scientific Research Institute of Abrasives and Grinding, 1968. Collection 1. - pp. 22-27.

[8] Netrebko V.P., Korotkov A.N. Durability of grinding wheels. Moscow: Agency of the Russian Press, 1992. - 104 p.

[9] A. Korotkov, D. Shatko. "Prospective Designs of Flap Grinding Wheels - New Opportunities and Approaches to Import Substitution of Grinding Tools", Applied Mechanics and Materials, Vol. 788, pp. 313-317, Aug. 2015.

[10] Korotkov A., Korotkova L., Gubaidulina R. Effect on grains form on performances grinding wheels. - Applied Mechanics and Materials, Vol. 682 (2014), p.p. 469-473. Trans Tech Publications, Switzerland.

[11] V. Korotkov, E. Minkin. Forecasting of operational indicators of grinding tools with the controlled form and orientation of abrasive grains. Materials Science and Engineering (2015) 012041.

[12] V. Korotkov, S. Petrushin. Research of Operational Characterizations of Cutting Discs with Oriented Abrasive Grains // Applied Mechanics and Materials - 2014. v. 682, pp. 224-230.

[13] V. Korotkov, E. Minkin. Forecasting of operational indicators of grinding tools with the controlled form and orientation of abrasive grains // IOP Conference Series: Materials Science and Engineering 91 (2015) 012041. doi:10.1088/1757-899X/91/1/012041

[14] V. Lyukshin, A. Barsuk, R. Fazleev. Cutting Capacity and Strength of Single Grinding Grains // IOP Conference Series: Materials Science and Engineering 91 (2015) 012047. doi:10.1088/1757899X/91/1/012047

[15] V. Lyukshin. Evaluation of Abrasive Grain Form // Applied Mechanics and Materials - 2014. v. 682, pp. 148-153.

[16] D. Shatko V. Lyukshin, V. Bakumenko. Performance Potential of Grinding Tools on Flexible Backing Produced of Grains with the Controlled Form. IOP Conference Series: Materials Science and Engineering, $\quad$ Volume $\quad 142, \quad$ Number 1. 